\title{
ANT LION OPTIMIZATION OF ON-GRID SUPPORTED BY PV/WIND CONSIDERING LIBYAN ENERGY
}

\author{
Abdulgader Alsharif \\ Division of Electrical Power Engineering, School of Electrical Engineering, Faculty of Engineering \\ Universiti Teknologi Malaysia, UTM, 81310, Skudai, Johor \\ Malaysia. \\ Technical College of Civil Aviation and Meteorology, Esbea \\ Libya \\ habdulgader@graduate.utm.my \\ Tan Chee Wei* \\ Division of Electrical Power Engineering, School of Electrical Engineering, Faculty of Engineering \\ Universiti Teknologi Malaysia, UTM, 81310, Skudai, Johor \\ Malaysia. \\ cheewei@utm.my \\ Razman Ayop \\ Division of Electrical Power Engineering, School of Electrical Engineering, Faculty of Engineering \\ Universiti Teknologi Malaysia, UTM, 81310, Skudai, Johor \\ Malaysia. \\ razman.ayop@utm.my
}

*Corresponding Author email: cheewei@utm.my

Peer-review under responsibility of 5th ASIA International Multidisciplinary Conference 2027 (Online) Scientific Committee http://connectingasia.org/scientific-committee/

(C) 2027 Published by Readers Insight Publisher,

Office \# 6, First Floor, A \& K Plaza, Near D Watson, F-10 Markaz, Islamabad. Pakistan,

editor@readersinsight.net

This is an open access article under the CC BY license (http://creativecommons.org/licenses/by/4.0/). 


\section{A B S T R A C T}

The increasing developments in Renewable Energy Sources (RESs) which provide benefits to address the growing future electricity demand need to be studied in depth. For better power performance to solve difficulties in power production, the On-grid system integrated with RESs can be adopted. This paper is aimed to shed light on two main RESs which are Photovoltaic (PV) and Wind Turbine (WT) with battery connected to the utility grid as an on-grid system to achieve the Sustainable Development Goal 7 (SDG7). In this paper, the Energy Management Strategy (EMS) is applied to achieve the objective functions which are Levelise Cost Energy (LCE), and Loss of Load Hours (LOLH), and to calculate the Greenhouse Gas (GHG) emission. Hence, Rule-Based EMS (RB-EMS) is supported to strategies the mechanism of the system by implementing a recent nature-inspired method namely Ant Lion Optimization (ALO). This paper encourages researchers to adopt the aforementioned method for solving problems due to the available benefits. The primary contribution of this article is to provide up-to-date and state-of-the-art knowledge to achieve the proposed objective functions of this study by utilizing MATLAB environment.

Keywords: On-Grid, ALO, RB-EMS

\section{RE SEARCH H I G L I G H T S}

1. Implementing ALO a recent nature-inspired and provide the best performance in comparision with the benchmarking methods.

2. The Rule-based energy management strategy as high supervisory control utilized due to its advantages.

3. The study area is blessed with high solar irridance to produce electrcity in the absence cases.

\section{Research Objectives}

This research will concentrate on the below objectives:

1. To utilize the Renewable Energy Sources (RESS) in the country to achive the Sustainable Development Goal 7 by using PV and WT $(1,2)$.

2. To minimize the Loss of Load Hours (LOLH) and Levelise Cost Energy (LCE) and compute the GHG as the bjective functions of the study using Antlion Optimzation for sizing the system compnents $(3,4)$.

3. To strategies the flown power in the system via Rule-Base-Energy Management Strategy using MATLAB (5).

\section{Methodology}

The mathedology used in this study is to size the components of system that shown in Fig. 1. using recent nature-inspired method namely Ant Lion Optimization (ALO) that introduced by Mirjalili (6). In addtion, the validation method utilized is Cuckoo Search Algorithm (CSA) that was initially developed by Yang And Deb in 2009 to solve structural optimization tasks $(7,8)$. Due to the simplicity of hybridization with other algorithms, fast 
convergence speed, which is suitable for many types of optimization problems ALO propoded $(9,10)$. As hygienic sources which naturally provided are generating green power. The PV and WTs are RESs that producing a green energy and having a much lesser negative environmental impact than the traditional fossil energy $(11,12)$. The climatology collected data illustrated in Fig. 2 sourced from the Centre for Solar Energy Research and Studies (CSERS) (13).

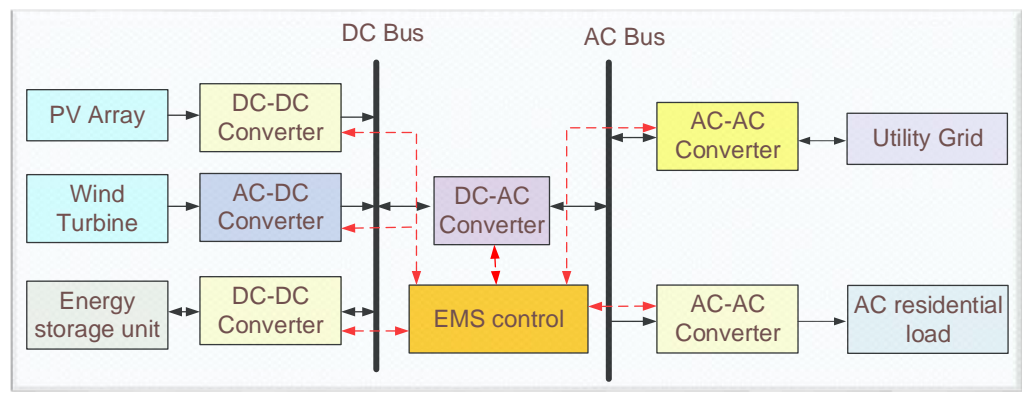

Fig. 1. Proposes microgrid system.
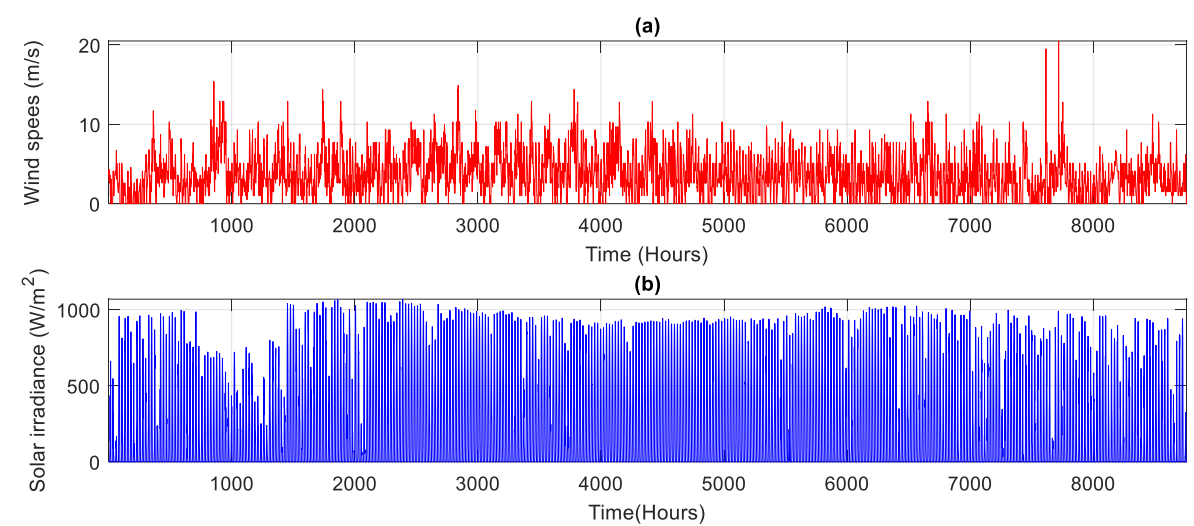

(c)

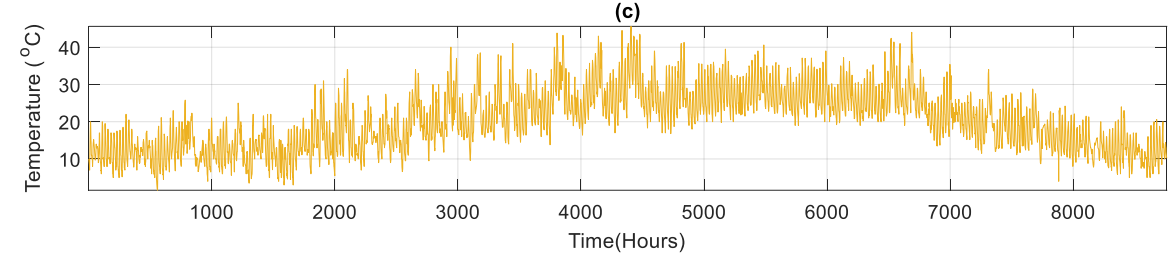

Fig. 2. Climatologically data (a) Wind speed, (b) Solar irradiance, (c) Ambient temperature.

The load profile of the four seasons in the area under study is demonstrated in Fig. 3. Where (a) is the contour plot load of the whole year, (b) is the seasonal load demand, and (c) is the daily load profile as collected from the General Electricity Company of Libya (GECOL) (14). The patterns of load are a constant during day or night time. 


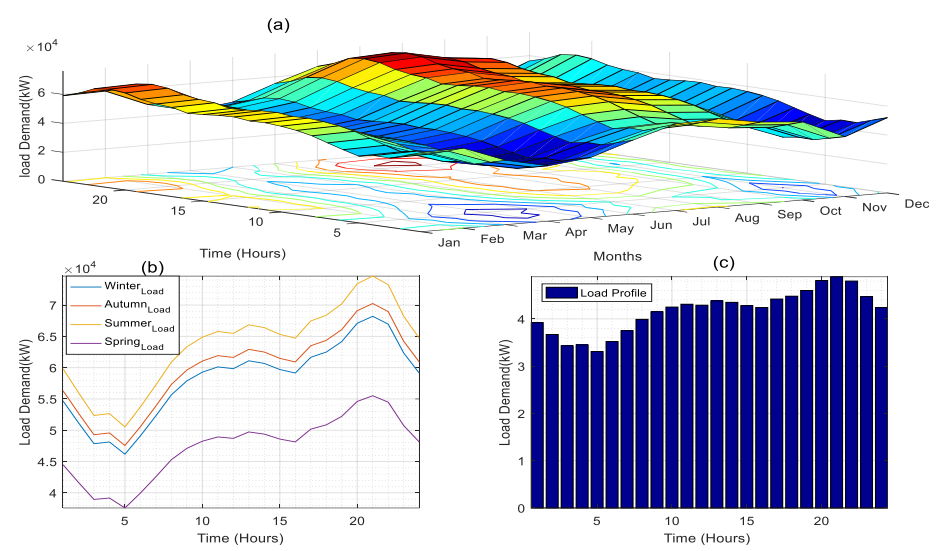

Fig. 3. Load profile (a) Annual Contour plot of the load demand, (b) four different seasons, (c) daily load profile

\section{Results}

In this case study, the proposed methodology is examined using the hourly data of wind speed, ambient temperature, solar irradiation, and load demand of Tripoli (Libya). The considered method in this article utilizes the mathematical equations to attain the investment costs and used the rule-based strategy to attain the objective function. The optimal result obtained from the driving methods are $0.28 \%, 0.60 \$ / \mathrm{kWh}$, and 2806 tone as LOLH, LCOE, and GHG, respectively.

\section{Findings}

Optimization systems are used to choose the optimum system with high energy, less cost, and less number of components to meet the load demand. In fact, the sizing of renewable energy sources is complicated compared with the conventional system due to the random nature of RESs cost (11). The widely RESs used are PV and WT due to the provision of green energy and flexibility of using the microgrid systems whether (On-grid or Off-grid). The obtained output power from the aforementioned sources are demonstrated in Fig. 4. While the optimal convergence of the two utilized algorithms is demonstrated in Fig. 5 it can be seen from the figure that the two methods have converge in almost 10 and 15 iterations, respectively. Additionally, the RB-EMS for the proposed system is illustrated in Fig. 6.

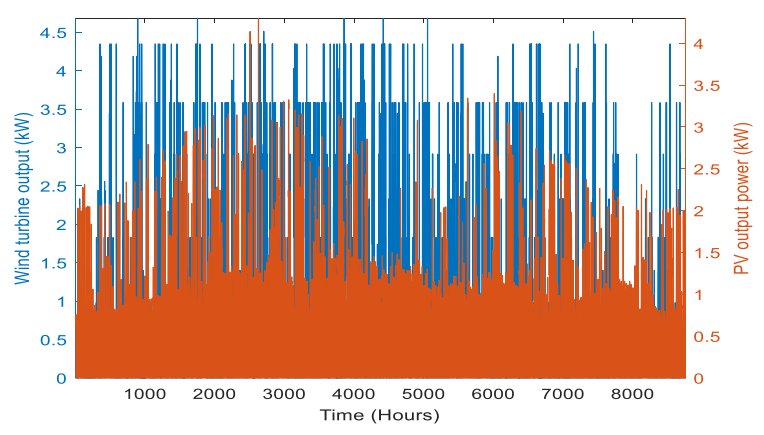

Fig. 4. Output generated power from PV and WT

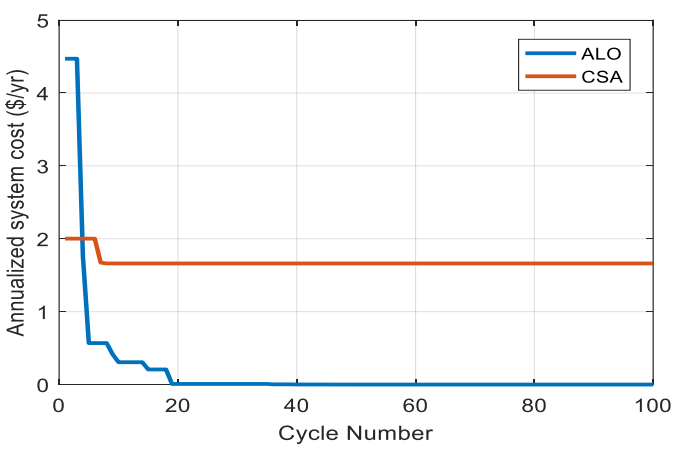

Fig. 5. Convergence progression of the proposed algorithms 


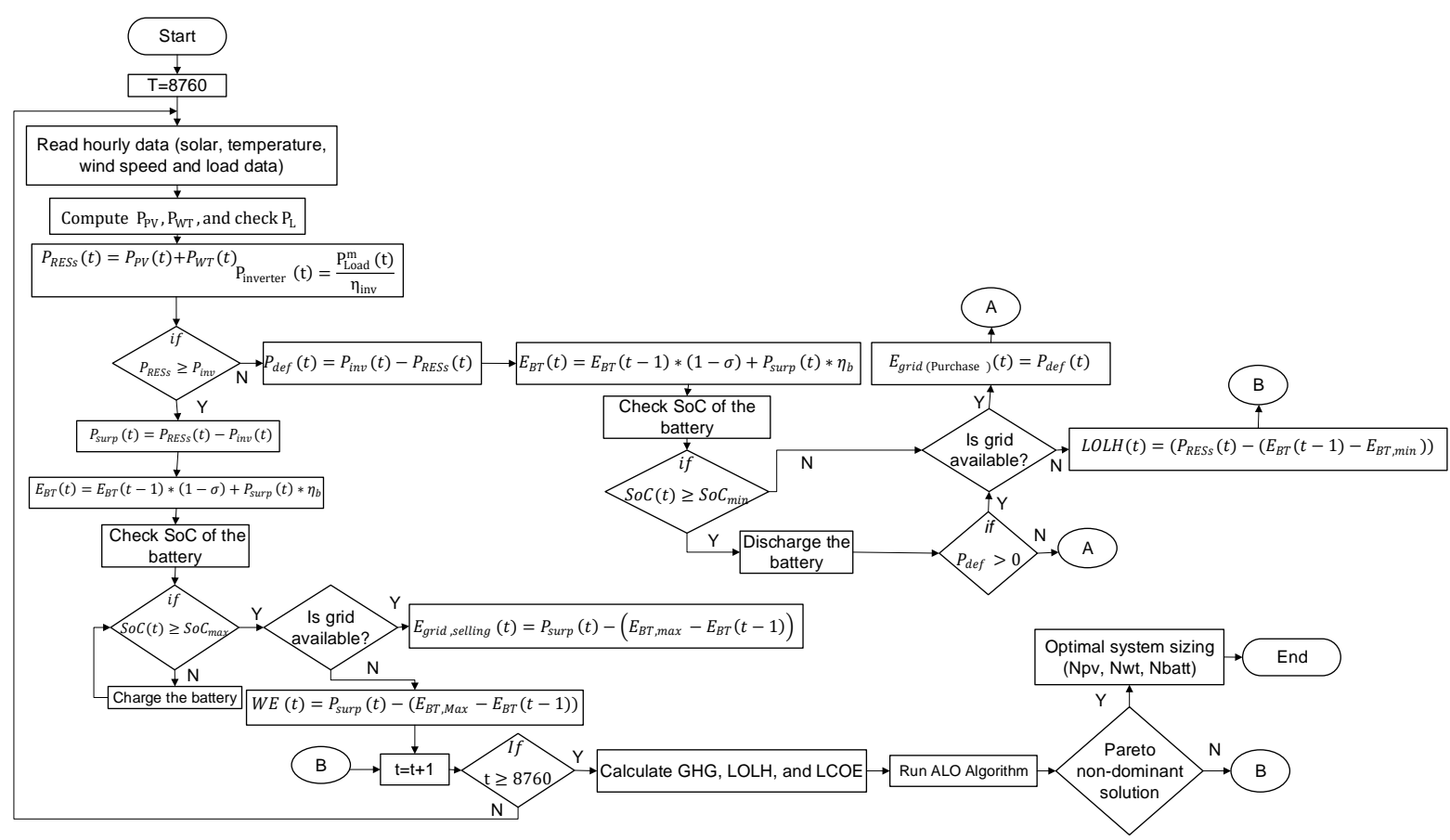

Fig. 6. Rule-based energy management strategy of the proposed system.

\section{Conclusion}

The aim of this study is to meet the load demand using the aforementioned RESs and examining them under Tripoli climatologically data. Additionally, to attaining the optimal number of batteries, solar panels, and wind turbines. As the two RESs (PV and WT) are analogous to each other in nature, they are capable of making a proper hybrid system to fulfil the load demand. Besides, using RESs in the area of study with the weather conditions can be considered as a great alternative to address power challenges. The number of components acquired from the proposed method for sizing show less number of elements resulting to less losses and cost over the year. From the flowchart of smooth power flow among the system components utilizing RB-EMS. From the obtained result from the ALO show that, the amount of cost and losses are less than the obtained from CSA. Matlab is utilized as a software to obtain the findings of numerical analysis simulation plots.

\section{Acknowledgement}

The authors would like to thank Universiti Teknologi Malaysia (UTM) for providing facility. They also acknowledge funding provided by UTM Shine under vote Q.J130000.2451.09G32. Finally, appreciation to colleagues in their direct and indirect support to the complication of this article.

\section{References}

1. Barakat S, Ibrahim H, Elbaset AA. Multi-objective optimization of grid-connected PVwind hybrid system considering reliability, cost, and environmental aspects. Sustain Cities Soc [Internet]. 2020 Sep; 60(9): 102178. Available from: https://linkinghub.elsevier.com/retrieve/pii/S0260691715001604 
2. Al-Shetwi AQ, Hannan MA, Jern KP, Mansur M, Mahlia TMI. Grid-connected renewable energy sources: Review of the recent integration requirements and control methods. J Clean Prod [Internet]. 2020;253:119831. Available from: https://doi.org/10.1016/j.jclepro.2019.119831

3. El-Hendawi M, Gabbar H, El-Saady G, Ibrahim E-N. Control and EMS of a Grid-Connected Microgrid with Economical Analysis. Energies [Internet]. 2018 Jan 5; 11(1): 129. Available from: http://www.mdpi.com/1996-1073/11/1/129

4. Mahdi S, Baygi H, Farzaneh J. Application of Artificial intelligence techniques for optimum design of hybrid grid-independent PV / WT / battery power system. Int J Ind Electron Control Optim. 2020; 3(3): 275-289.

5. Herath A, Kodituwakku S, Dasanayake D, Binduhewa P, Ekanayake J, Samarakoon K. Comparison of Optimization- and Rule-Based EMS for Domestic PV-Battery Installation with Time-Varying Local SoC Limits. J Electr Comput Eng. 2019;2019.

6. Mirjalili S. The ant lion optimizer. Adv Eng Softw [Internet]. 2015; 83: 80-98. Available from: http://dx.doi.org/10.1016/j.advengsoft.2015.01.010

7. Gandomi AH, Yang X-S, Alavi AH. Cuckoo search algorithm: a metaheuristic approach to solve structural optimization problems. Eng Comput [Internet]. 2013 Jan 29;29(1):1735. Available from: http://link.springer.com/10.1007/s00366-011-0241-y

8. Fister I, Yang X-S, Fister I, Brest J, Fister D. A Brief Review of Nature-Inspired Algorithms for Optimization. Elektroteh Vestnik/Electrotechnical Rev [Internet]. 2013 Jul 16; 80(3): 116-122. Available from: http://arxiv.org/abs/1307.4186

9. Abualigah L, Shehab M, Alshinwan M, Mirjalili S, Elaziz MA. Ant Lion Optimizer: A Comprehensive Survey of Its Variants and Applications. Arch Comput Methods Eng [Internet]. 2020;(0123456789). Available from: https://doi.org/10.1007/s11831-020-09420-6

10. Banadkooki FB, Ehteram M, Ahmed AN, Teo FY, Ebrahimi M, Fai CM, et al. Suspended sediment load prediction using artificial neural network and ant lion optimization algorithm. Environ Sci Pollut Res [Internet]. 2020 Oct 3;27(30):38094-116. Available from: http://link.springer.com/10.1007/s11356-020-09876-w

11. Khan FA, Pal N, Saeed SH. Review of solar photovoltaic and wind hybrid energy systems for sizing strategies optimization techniques and cost analysis methodologies. Renew Sustain Energy Rev [Internet]. 2018; 92: 937-947. Available from: https://www.sciencedirect.com/science/article/pii/S136403211830323X

12. Akram U, Khalid M, Shafiq S. Optimal sizing of a wind/solar/battery hybrid gridconnected microgrid system. IET Renew Power Gener [Internet]. 2018 Jan 8;12(1):72-80. Available from: https://digital-library.theiet.org/content/journals/10.1049/ietrpg.2017.0010

13. Climitology Data [Internet]. The Center for Solar Energy Research and Studies, Libya. [cited 2020 Nov 24]. Available from: http://csers.ly/en/

14. General Electricity Company of Libya (GECOL) [Internet]. 2021 [cited 2021 Mar 24]. Available from: https://www.gecol.ly/gecol_en/ 


\section{Author's Biography}

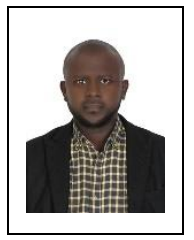

Abdulgader Alsharif, recived the bachelar's degree in communication engineering from technical college of civil aviation and meteorology, Esbea, Libya in 2011. He recived the master's degree in electric and electronic engineering from University of Turkish Aeronautical Association, AnkaraTurkey in 2016. Recived the second master degree's in electric and computer engineering from Altınbaş University-Istanbul- Turkey in 2018. Currently he is a PhD candidate in Universiti Teknologi Malaysia (UTM) from the beginng of 2020. His research interests include renewable energy sources, Energy management strategies and sizing of the integrating systems with Vehicle to Grid (V2G).

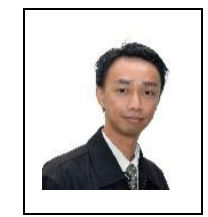

Chee Wei, Tan received his B.Eng. degree in Electrical Engineering (First Class Honors) from Universiti Teknologi Malaysia (UTM), in 2003 and a Ph.D. degree in Electrical Engineering from Imperial College London, London, U.K., in 2008. He is currently an associate professor at Universiti Teknologi Malaysia and a member of the Power Electronics and Drives Research Group, School of Electrical Engineering, Faculty of Engineering. His research interests include the application of power electronics in renewable/alternative energy systems, control of power electronics and energy management system in microgrids.

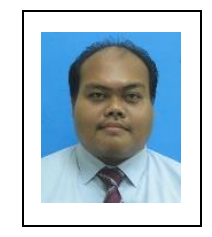

Razman Ayop, received the bachelor's degree in electrical engineering with first-class honours, the master's degree in electrical engineering with specialization in power system, and the PhD degree in electrical engineering from Universiti Teknologi Malaysia (UTM), Johor, Malaysia, in 2013, 2015, and 2018, respectively. He is a Senior Lecturer with UTM and a member of Power Electronics and Drives Research Group (PEDG), UTM. His research interests include renewable energy and power electronics. This includes the photovoltaic (PV) emulator, maximum power point tracking (MPPT) converter, standalone energy management and sizing, $P V$ modelling, vehicle to grid (V2G) system, and fuzzy logic controller. 